\title{
White Caribbean
}

National Cancer Institute

\section{Source}

National Cancer Institute. White Caribbean. NCI Thesaurus. Code C77816.

A person having origins in the Caribbean region who identifies as white. 